\title{
Lifetime of wood as related to strength distribution
}

\author{
Nielsen, Lauge Fuglsang
}

Publication date:

1991

Document Version

Publisher's PDF, also known as Version of record

Link back to DTU Orbit

Citation $(A P A)$ :

Nielsen, L. F. (1991). Lifetime of wood as related to strength distribution. Technical University of Denmark, Department of Civil Engineering.

\section{General rights}

Copyright and moral rights for the publications made accessible in the public portal are retained by the authors and/or other copyright owners and it is a condition of accessing publications that users recognise and abide by the legal requirements associated with these rights.

- Users may download and print one copy of any publication from the public portal for the purpose of private study or research.

- You may not further distribute the material or use it for any profit-making activity or commercial gain

- You may freely distribute the URL identifying the publication in the public portal

If you believe that this document breaches copyright please contact us providing details, and we will remove access to the work immediately and investigate your claim 
Reliability-Based Design of Engineering Wood Structures NATO - Advanced Research Workshop

Florence, Italy - June 3-6-1991

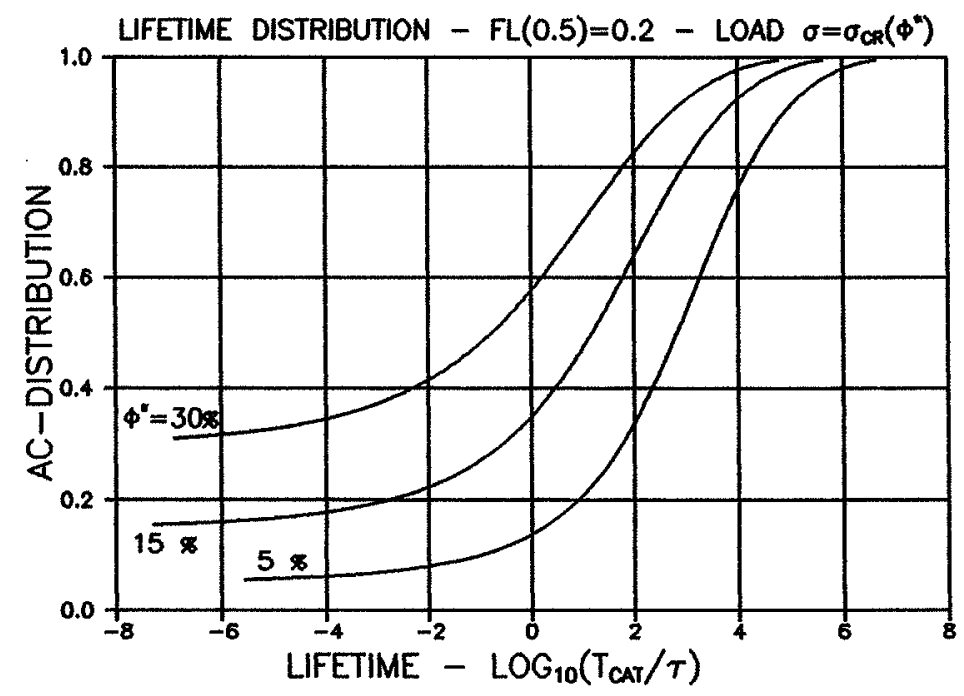





\title{
Lifetime of Wood as related to Strength Distribution \\ Lauge Fuglsang Nielsen \\ Building Materials Laboratory \\ Technical University of Denmark \\ DK-2800 Lyngby, Denmark
}

\begin{abstract}
Lifetime of wood is related to load level as well as wood quality. The latter statement has been justified in recent years both theoretically and experimentally. It is demonstrated in the paper that lifetime distribution is also related to quality, meaning that lifetime distribution can be predicted from strength distribution. An algorithm is developed for this purpose - and a discussion is made on how to extract relevant lifetime information from experimental data. It is finally pointed out that the analy sis presented is valid also when a number of other building materials are considered.
\end{abstract}

\section{INTRODUCTION}

Any realistic reliability study of structures needs information on how reliable are the building materials being used. A reliability analy sis of a wood structure, for example, cannot be made without knowing about strength and lifetime distributions of the wood considered as structural material. Normally, purely empirical distributions are chosen without any guaranty that this procedure will not introduce inconsistency which may influence in some un-known way the result of a reliability analysis.

These considerations indicate the topic of the present paper. It is demonstrated that the two distributions considered are correlated, meaning that lifetime distribution can be predicted from strength distribution. An algorithm is developed for this purpose - and a brief discussion is made on how to extract relevant lifetime information from experimental data.

$\begin{aligned} \text { Table } 1 \text { - List of symbols } & \\ \text { Theoretical strength: } & \sigma_{\mathrm{t}} \\ \text { Real (short time) strength: } & \sigma_{\mathrm{cr}} \\ \text { Strength level (Materials quality): } & \mathrm{FL}=\sigma_{\mathrm{cr}} / \sigma_{\mathrm{t}} \\ \text { Load: } & \sigma \\ \text { Load level: } & \mathrm{SL}=\sigma / \sigma_{\mathrm{cr}} \\ \text { Time: } & \mathrm{t} \\ \text { Creep power: } & \mathrm{b} \\ \text { Relaxation (creep doubling) time: } & \tau \\ \text { Time to catastrophic failure: } & \mathrm{t}_{\mathrm{cat}}\end{aligned}$




\section{ANALYSIS}

Wood is a damaged viscoelastic material which becomes weaker as damages approach their critical sizes. This materials concept (DVM-concept) has been developed by the author in recent years (e.g. 1,2,3,4,5) to explain and predict successfully a number of wood mechanical properties such as lifetime and residual strength under static and varying load. DVM-expressions relevant for the analysis of deadload lifetime are summarized in Section 2.1. The distribution of lifetime is then studied by "experiments" where a group of wood is subjected to constant loads chosen from the lower end of associated strength distribution.

The symbols used in the analysis have the meanings listed in Table 1. Methods of estimating strength levels and creep parameters of wood are suggested by the author in $(4,5)$. Strength level, for example, is estimated by the following (simplified) expression

$$
F L=\sqrt{1-e^{-d / R}} ; \quad(\approx \sqrt{d / R} \text { at } R / d>10)
$$

where $R$ and $d \approx 0.3 \mathrm{~mm}$ denote defect radius (e.g. crack, knot, cross-sawing) and defect nucleus diameter respectively. The latter quantity refers to "virgin clear wood" where no real defect has yet been developed. Reference strength, $\sigma_{\ell}$, is strength of virgin clear wood substance between defect nuclei. Structural wood and clear wood have strength levels FL $<0.2-0.3$ and $0.2-0.3<\mathrm{FL}<0.8$ respectively. Virgin clear wood has $F L \approx 0.8$ (at $d / R \approx 1)$. Strength ratios of $F L$ $>0.8$ can only be obtained by "healing" the damage structure of virgin clear wood such that any defect nucleus becomes smaller.

The creep parameters, $\tau$ and $b$, define local creep of wood at crack vicinities by the well-known Power-Law creep function formulated as follows by the author in (6)

$$
C(t)=1+(t / \tau)^{b}
$$

with a creep power of $b \approx 0.25$ and a relaxation time of $\tau \approx 10^{1 \pm 1}$ days (bending, dry at $20^{\circ} \mathrm{C}$ ) as suggested by the author in $(4,5)$. The relaxation time is very sensitive to climate. The actual value, however, is of no interest in the present context as the analysis is based on non-dimensional time $(t / \tau)$.

The quality of the DVM-theory to operate with non-dimensional time is very fortunate in lifetime analy sis. Lifetime is predicted to be proportional to relaxation time - and the influence on lifetime of temperature and moisture is easily considered (e.g. 4). The DVM-theory operates in general with non-dimensional quantities (streng th level, load level, damage ratio) which makes it independent of orthotropy and mode of loading when wood is considered - and which qualifies the method also as a so-called damage accumulation theory.

\subsection{Lifetime expressions}

Deadload lifetime, $t_{\text {cat }}$, of a damaged viscoelastic material like wood is predicted by the following relation presented in (5)

$$
\frac{t_{\text {cat }}}{\tau}=(A-1)^{1 / b}+\frac{B q}{C} H(\mu)
$$


where the parameters involved have the meanings expressed by Equations $4-$ 10. The limit quantities in parenthesis apply at low strength levels (FL $\rightarrow 0$ ).

$$
\begin{aligned}
& q=\sqrt{(1+b)(2+b) / 2} \\
& A=\frac{\ln (\cos (\pi F L / 2))}{\ln (\cos (\pi F L * S L / 2))} \quad ; \quad\left(A \rightarrow S L^{-2}\right) \\
& B=\beta+(1-\beta) * \cos (\pi * F L * S L / 2) \quad ; \quad(\beta=(4-b) / 5) ; \quad(B \rightarrow 1) \\
& C=1-\cos (\pi * F L * S L / 2) \quad ; \quad\left(C \rightarrow(\pi * F L * S L)^{2} / 8\right) \\
& H(\mu)=\int_{0}^{\mu} \frac{x^{1 / b}}{1+x} d x \\
& \mu= \begin{cases}A * B-1 & \text { when } A * B \geq 1 \\
0 & \text { when } A * B<1\end{cases}
\end{aligned}
$$

In general $H(\mu)$ can only be determined numerically. For special creep powers, however, the integral involved can be developed analytically. Some useful examples are given in (5). For $b=1 / 4$ which is used in the present study we get

$$
H(\mu)=\frac{\mu^{4}}{4}-\frac{\mu^{3}}{3}+\frac{\mu^{2}}{2}-\mu+\ln (\mu+1) \quad(b=1 / 4)
$$

\subsection{Strength and load distributions}

We now consider a group of wood defined by a characteristic strength distribution which we will fit non-dimensionally with respect to the 50-percentile strength, $\sigma_{\mathrm{cr}}(0.5)$. A number of mathematical expressions are available for this purpose. We suggest a very simple one, namely

$$
Z=Z(\Phi)=\frac{\sigma_{\text {crI }}(\Phi)}{\sigma_{\text {cr }}(0.5)}=\left(\frac{a+\Phi}{1+a-\Phi}\right)
$$

$Z=Z(\Phi)$ is the $\Phi$-percentile (relative)strength, while a and d are characteristic distribution parameters. The example shown in Figure 1 with $(a, d)=(0.01,0.20)$ is a reasonable order of magnitude estimate of a strength distribution for structural wood. (The parameter, $\Phi$, will subsequently also be referred to as "member number" in an array where members of the group are ranked from $\Phi$ $=0$ to $\Phi=1$ by increasing strength).

The strength level of each member (number $\Phi$ in Figure 1) is expressed by $Z$ as follows where the 50-percentile strength level is given by $F L(0.5)=\sigma_{c r}(0.5) / \sigma_{\ell}$. 


$$
F L(\Phi)=F L(0.5) * Z(\Phi)
$$

It has previously been indicated that normal wood has a strength level which cannot exceed 0.8. This means that Equation 11 (or another approximation) and Equation 12 are tied together by the following condition

$$
Z(1) * F L(0.5) \leq 0.8
$$

Each member experiences the following load level when the group is loaded with $\sigma$. The latter term in Expression 14 applies when $\sigma$ appears in the strength distribution as $\sigma=\sigma_{\mathrm{cr}}(\Phi)$, (see Figure 1).

$$
S L(\Phi)=\frac{\sigma / \sigma_{C I}(0.5)}{Z(\Phi)} ; \quad\left(=\frac{Z\left(\Phi^{*}\right)}{Z(\Phi)} \quad \text { at } \quad \sigma=\sigma_{\mathrm{CI}}\left(\Phi^{*}\right)\right)
$$

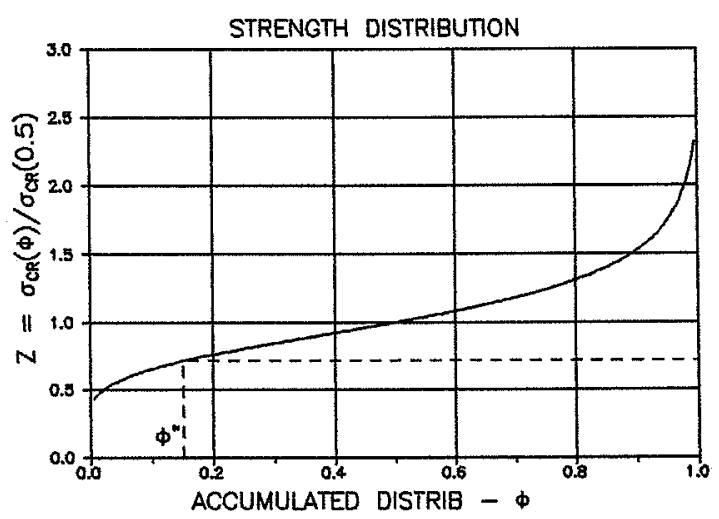

Figure 1. Strength distribution according to Equation 11 with $(a, d)=(0.01$, $0.20)$.

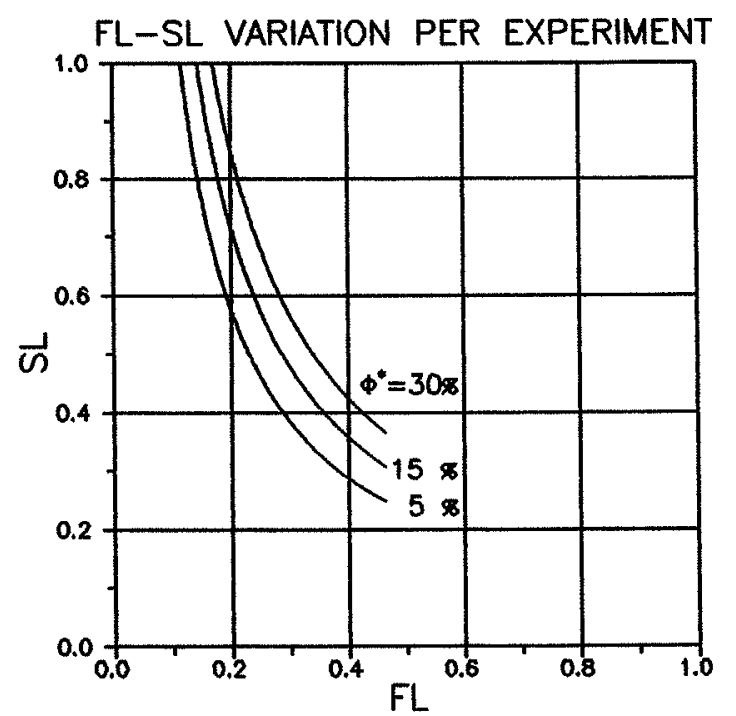

Figure 2. Variation in strength level and load level according to Equations 12 and 14 respectively. $F L(0.5)=0.2$. Strength distribution from Figure 1. 
The variations of strength level and load level per "experiment" defined in the following section are predicted by Equations 11, 12, and 14 and presented graphically in Figure 2. A load level of SL $>1$ is not possible, meaning that the members with $\Phi \leq \Phi$ will fail during the process of loading.

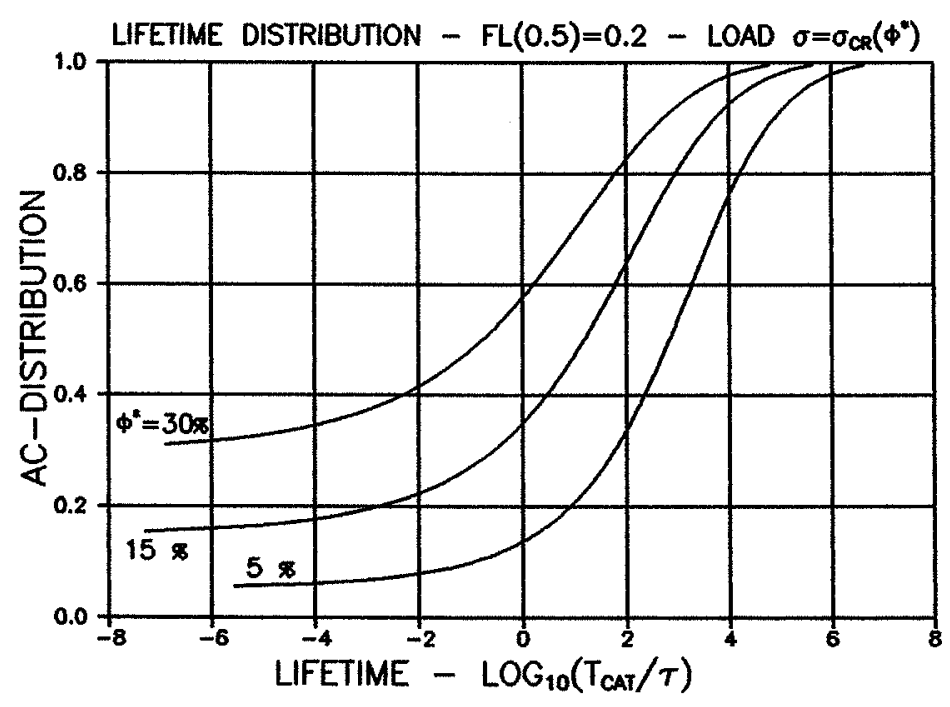

Figure 3. Lifetime distributions associated with the strength distribution given in Figure 1 and loads as indicated.

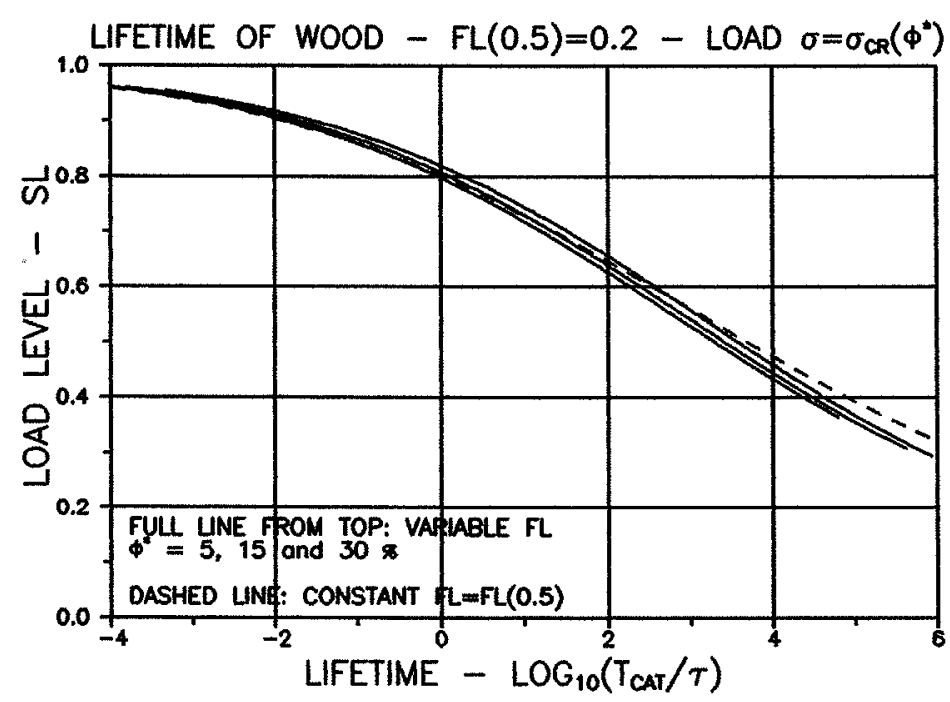

Figure 4. Lifetime of wood recorded at constant loads as indicated. Wood quality is $F L(0.5)=0.2$ with strength distribution given in Figure 1.

\subsection{Lifetime distribution - an example}

A group of wood with shorttime strength defined by the distribution given in Figure 1 is used in three lifetime "experiments" with loads given by the 5-, 15-, and 30-percentile strength, i.e. $\sigma=\sigma_{\mathrm{cr}}(0.05), \sigma_{\mathrm{cr}}(0.15)$, and $\sigma_{\mathrm{cr}}(0.30)$ respectively. A creep power of $b=0.25$ is estimated as suggested in (5).

Algorithm: Lifetime for each member (number $\Phi$ ) of the group is predicted by Equations $3-10$ with streng th level and load level determined by Equations 12 and 14 respectively with $\Phi$ going from 0 to 1 , see Figure 2 . 
Lifetime distribution: The lifetime of each member is related to its number $(\Phi)$ in Figure 3 which then represents the distributions of lifetimes obtained in our experiments.

Lifetime: The $t_{\text {cat }}-\mathrm{SL}$ results are shown by full lines in Figure 4 . Notice that each graph represents a constant load on a material of varying quality (members with different damage structures). The true lifetime of a certain quality wood is constructed by connecting points of equal FL between graphs. It is, however, remarkable how qualified a lifetime estimate in our example can be obtained directly from Figure 4. Apparently the effects of SL getting lower and FL getting higher with increasing $\Phi$ neutralize each other practically such that lifetime at some average strength level is well described by data from only one experiment. This statement is justified comparing the full lines of Figure 4 with the dashed line which is lifetime as predicted at a strength level of FL $\equiv \mathrm{FL}(0.5)$. It should be noticed, however, that broader selected wood (than defined by Figure 1 approximately) will increase separation between the graphs of Figure 4 and reduce the quality of the simple lifetime prediction method.

\section{CONCLUSIONS AND FINAL REMARKS}

The constant load "experiments" made in Section 2 show that lifetime observations may differ by approximately 4 decades between load levels, SL $\approx 0.9$ and $\mathrm{SL} \approx 0.6$. This is an order of magnitude also met in real experiments (e.g. 7,8$)$. It seems then justified to suggest that lifetime distribution is in fact a logical consequence of strength distribution.

Each experimental lifetime observation reflects the behavior of an individual and should be respected as such. This feature has been considered in Section 2 from which the following summarized procedure is suggested to obtain a maximum of lifetime information from experiments: Lifetime data from a number of constant load experiments are plotted (as in Figure 4) against individual load ratios determined by Equation 14. Each point is marked with its strength level according to Equation 12. Lifetime of wood of quality "FL" is then constructed by connecting data points marked "FL" between graphs.

A simplified version of this procedure is justified by the example of Section 2.3: When wood is better selected than given by Figure 1 approximately we may skip the "FL- marking" and consider the lifetime-SL graph (obtained by only one experiment) directly as real lifetime applying to the average quality of the wood material considered. Smaller sections, however, of lifetime information are described in this way as selection quality increases $(d \rightarrow 0$ in Equation 11). The well-known Borg Madsen method (e.g. 7,9$)$ of treating experimental lifetime data is consistent with the simple procedure just described. The statement made in Section 2.3 that $\mathrm{T}_{\text {cat }}-\mathrm{SL}$ graphs come closer when materials selection becomes narrower complies well with the experimental data reported in $(7,8)$ with (8) representing the narrower selection.

Finally, it should be mentioned that the results presented in this paper are valid in principle for any building material which can be modelled like a damaged viscoelastic material. This feature is explained in more details in $(4,5)$.

\section{Literature}

1. Nielsen, L. Fuglsang: "Crack Propagation in Linear-Viscoelastic Materials" (in danish with extended english summary), Bygningsstatiske Meddelelser, 49(1978), $1-45$.

2. Nielsen, L. Fuglsang: "Crack Failure of Dead-, Ramp-, and Combined Loaded Viscoelastic Materials", First Int. Conf. on Wood Fracture, Banff, Alberta, 
Canada, 1978. Proc. Western Forest Products Lab., Univ. Brit. Columbia, Vancouver, Canada, 1979, $187-200$.

3. Nielsen, L. Fuglsang and Kousholt, K.: "Stress-Strength-Lifetime Relationship for Wood". Wood Science, 12(1980), 162-164.

4. Nielsen, L. Fuglsang: "Lifetime and fatigue of wood and other building materials subjected to static and repeated loads". IUFRO-Engineering Group Conference 1990, Saint John, New Brunswick, Fredericton, N.B., Canada. Proc. Techn. Univ. Denmark, Build. Mat. Lab., Copenhagen, 1991 (in press).

5. Nielsen, L. Fuglsang: "Lifetime, Residual Strength, and Quality of Wood - and other viscoelastic building materials". Holz als Roh- und Werkstoff, 1991, in press.

6. Nielsen, L. Fuglsang: "Power Law Creep as related to Relaxation, Elasticity, Damping, Rheological Spectra and Creep Recovery - With Special Reference to Wood". IUFRO-Engineering Group Conference 1984. Xalapa, Mexico. Proc. Techn. Univ. Denmark, Build. Mat. Lab., Copenhagen, 1984, 181-204.

7. Madsen, B. and Johns, K.: "Duration of Load Effects in Lumber, Part II: Experimental Data". Can. J. Civ. Eng., 9(1982), 515-525. - Johns, K. and Madsen, B.: "...Part I: A Fracture Mechanics Approach". Can. J. Civ. Eng., 9(1982), 502-514. - Madsen, B. and Johns, K.: ".... Part III: Code Considerations". Can. J. Civ. Eng ., 9(1982), 526-536.

8. Hoffmeyer, P.: "Failure of wood as influenced by moisture and duration of load". Thesis, Dept. Environmental Science and Forestry, State Univ. of New York, Syracuse, N.Y., 1990.

9. Madsen, B.: "Duration of load tests for dry lumber in bending". Struct. Res. Series, Report No 3, 1971. Civ. Eng. Dept., Univ. Brit. Columbia, Vancouver B.C., Canada. 